\title{
Management of energy distribution and development of Arctic energy resources
}

\author{
Sergey Agarkov ${ }^{1}$, Sergey Kozmenko ${ }^{1}$, Anton Saveliev ${ }^{1}$, and Anna Teslya ${ }^{2, *}$ \\ ${ }^{1}$ Murmansk State Technical University, Sportivnaya Ulitsa, 13, Murmansk, Murmanskaya obl., \\ 183010, Russia \\ ${ }^{2}$ Peter the Great St.Petersburg Polytechnic University, Polytechnicheskaya, 29, St. Petersburg, \\ 195251, Russia
}

\begin{abstract}
The study is aimed at the issued of environmental planning and management of energy resource extraction in the Russian Arctic Zone. The paper presents a systematic overview of the factors currently hindering comprehensive analysis of the consequences of intensified industrial development of energy resources, and consequently, effective managerial decision-making counteracting negative environmental impacts in the Russian Arctic. The environmental safety of oil and gas facilities on the shelf greatly depends on a system for continuous environmental monitoring, which allows developing measures to reduce environmental risks. There were formulated the main provisions of environmental monitoring as an element of the environmental planning system for facilitating effective managerial decision-making in industrial development of Arctic energy resources.
\end{abstract}

\section{Introduction}

Active industrial development of energy resources in the Arctic while preserving the environmental status is impossible without proper environmental monitoring, which should be an important element of modern environmental planning, serving as the basis for making management decisions. It is evident that industrial extraction of energy resources and the anthropogenic impact on the Arctic territories are going to increase. The current methods used for monitoring are insufficient for obtaining all the necessary information. The Arctic Zone of the Russian Federation is of key importance for the country's strategic interests, ensuring its socio-economic development and its national security whose most crucial elements are energy and raw materials. A global logistics system, based on consistent and systematic modernization of transport communications of the Northern Sea Route and complying with modern environmental standards, should be devised to support management of energy distribution and controlled development of the Arctic territories. It seems logical that this complex and multifaceted problem can be best solved by making the Russian Arctic an independent object of state policy.

The expanding scale of economic activity, with new systems designed for management of energy distribution and management, as well as for monitoring and control of new

\footnotetext{
*Corresponding author: anntes@list.ru
} 
megaprojects for developing the Arctic region (including projects for developing the energy resources of the continental shelf) means that digital technologies have to be introduced for monitoring, studying, processing, extracting and transporting mineral and energy resources, ensuring the environmental safety of modern projects and adopting new environmental standards. The Government of the Russian Federation set out a wide range of tasks with rather tight deadlines, which greatly complicates the challenge of protecting the Arctic's vulnerable environment with its low self-sustaining and self-healing capacities. Thus, environmental planning is an essential part management of energy distribution and use in the Arctic. Environmental planning and management should include, as a matter of priority, a system of measures aimed at preventing manmade disasters in construction and operation of drilling platforms and sea transport of hydrocarbons.

The emerging new technologies, transition to digital production controlled by intelligent systems, the possibility of environmental monitoring in real time with the prospect of creating a global unified network are the factors offering new opportunities for monitoring the industrial development of the Arctic's energy resources and, ultimately, for establishing a new environmentally integrated energy economy.

\section{Analysis of achievements and experience}

In recent years, Russian and foreign scholars have been actively searching for new methods of organizing economic activity that allows complying with environmental standards while ensuring economic growth. Shipping, fishing and tourism are rapidly expanding industries with high potential, contributing to sustainable development of the Arctic [1]. Any projects in the Arctic, for example, the tourism business, should be analyzed not so much from the standpoint of financial costs and benefits but taking into account the impact of the projected changes on the environment and on the socio-economic sphere [2].

While the above-mentioned industries are undoubtedly important, the main reason for interest in Arctic development is in economic factors, as well as in enormous reserves of natural resources, including hydrocarbons such as oil and gas, found in this region [3]. Russia ranks first in the world in terms of proven reserves of natural gas (estimated as 50.5 trillion cubic meters or $25.2 \%$ of the world's total in 2016) and in seventh in terms of proven oil reserves ( 80 billion barrels or $5.4 \%$ of the world's total in 2016). Russia ranks second after the United States for gas production (about 17.5\% of the world's total in 2016).

With emerging new technologies and the evolving digital economy, non-Arctic states of the European Union, and even such remote countries as India, China, South Korea, Brazil and Japan making claims for the Arctic territories [4-5]. This means that the environmental pressure on the Arctic is going to rapidly increase.

Negative impact on marine organisms and ecosystems of the Arctic starts with geological and geophysical surveys. Subsequent stages and operations of exploration, extraction and transportation of hydrocarbons, accompanied by discharge of liquid and solid waste, further aggravate the negative impact on biological habitats [6-7].

Heavier environmental pressure on the Arctic ecosystem is additionally intensified by industrial production in other countries. Toxic substances are most often carried to the Arctic:

- through the waters of the Gulf Stream from the North Sea (radioactive materials from nuclear waste reprocessing facilities in England and France);

- with the effluents from Amu Darya and Syr Darya in the Aral Sea and with dust storms through the upper atmosphere and the zone of high-altitude jet streams (pesticides);

- with high-altitude air flows from Europe, North America, China, South Korea and Japan (mercury, lead, cadmium) [8].

Extensive industrial development of hydrocarbons in the Russian Arctic shelf brings to the forefront the issue of organizing a modern environmental monitoring system. Ensuring 
environmental safety is extremely important for the Arctic seas, since low temperatures, ice, slow waves, low chemical and biological activity all make marine ecosystems very vulnerable [9].

On the one hand, climate change in the Arctic, along with new technologies introduced, generates favorable trends for socio-economic growth in the region; on the other hand, it is exactly these trends that are going to eventually have a negative impact [10]. The programs for development of marine environments adopted by the Arctic countries have long-term economic and environmental consequences for the world community [11].

International research in the field of environmental protection in the Arctic is aimed at finding effective ways to protect the biodiversity of the region's marine ecosystems, involving active integration of information technologies. For example, a network of protected marine areas can be built using a methodology based on the MARXAN decision support tool, complemented by extensive post-analysis [12]. Similar studies have focused on using digital information technologies for creating an integrated monitoring system of the Caspian Sea [13-14]; this experience might be of interest as reference for solving problems in the Arctic.

Studies on the current environmental situation and biodiversity in industrial development regions using approved environmental monitoring methods (with the Barents Sea shelf as an example [7]) have established that the methods used do not yield a comprehensive assessment of the current environmental conditions and biodiversity in Arctic territories of intensive industrial development.

Modern environmental planning and management for developing the Arctic region is impossible without a unified information system for environmental monitoring of the Arctic territories, which is largely possible through new computer technologies, digitized business processes, cloud technologies for storing large amounts of information [15]. Many Russian companies are ready to use the latest technologies, including in the management of business processes in the Arctic [16-17].

Thus, management of energy distribution and use, analysis of economic and environmental losses is requires by building environmental safety system for the Arctic; this is a key task that can be implemented at present; this is a key task that can be implemented at present.

\section{Barriers to organization of environmental planning and management}

The studies carried out on environmental planning and development of the Russian Arctic have revealed that the only necessary condition for reconciling the conflicting interests of different companies involved in developing the energy resources in the Arctic is using innovative technologies that help stimulate economic growth and preserve the Arctic environment by modernizing and improving production efficiency [18].

For example, environmental safety of oil and gas facilities on the shelf, which include engineering structures for extraction of petroleum hydrocarbons and the associated transport infrastructure, is largely ensured by effective systems for monitoring the environmental status and the natural and man-made factors affecting it. Such monitoring allows taking into account the economic risks, developing a system of measures to reduce the risks, making it an essential element of environmental planning.

Meanwhile, financing environmental projects in large territories is a serious problem needing a systemic approach to managing tasks related to environmental matters. Growing anthropogenic impact on the shelves means that strict and reliable control should be established over the state of the natural environment, not only in areas of industrial activity, but also over much wider territories, since environmental incidents generally spread beyond license blocks. A systemic approach to solving problems of environmental management 
should integrate legal and informational bases and computer technologies for data collection, processing and analysis. While the evolving digital economy opens up new opportunities, they are still hindered by numerous factors, including the following:

1. The legal framework regulating the monitoring of wildlife habitats on the continental shelves is poorly developed and coordinated. This framework consists of laws and regulations of different levels: from international conventions ratified by Russia to departmental instructions and guidelines issued by different agencies [19]. No consistent regulations have been worked out for protecting the marine environment and ensuring the safety of developing hydrocarbon deposits on the continental shelf. Some regulations dating back to the Soviet period are virtually defunct at present, or need to be considerably updated. The legal framework is inconsistent and uncoordinated, making it difficult to interpret and apply the existing regulations or find gaps in the legislation.

2. Corporate regulatory documents are incomplete. Since current legislation does not provide comprehensive regulations, companies tend to rely on their own corporate documents. (For example, Gazprom PJSC developed the standards STO Gazprom 2-1.19275-2008 "Environment protection at enterprises of PJSC Gazprom. Operational Environmental Control. General requirements" and STO Gazprom 2-1.19-415-2010 "Environmental monitoring. General requirements".) Such documents were primarily developed for land objects without taking into account the specifics of oil and gas production on the Arctic shelf (a remote and vulnerable area lacking infrastructure, with short daylight hours and covered with ice). Corporate documents are focused on achieving the specific goals and objectives of the company, without accounting and compensating for all negative environmental impacts, which is why these documents cannot serve as a basis for environmental planning and development.

3. The sectoral approach to developing natural resources, historically evolved in Russia, is not suitable for the Arctic. All problems connected with ensuring environmental safety of production, ensuring environmental planning and managing the development of the territory and solving fiscal environmental problems cannot be solved at the present level of division of labor within a single industry or a single corporation.

4. The system for environmental control and managing the development of the Russian Arctic currently lacks an integrated approach, which is an issue that has been repeatedly pointed out in studies, for example, [20]. At present, the Russian Arctic Zone is neither a separate entity of a unified information system for environmental monitoring, nor a separate economic entity (in particular, in what concerns the development of energy resources), nor a separate entity of environmental planning and management. Monitoring is carried out by the Federal Service for Hydrometeorology and Environmental Monitoring (Roshydromet) with its subdivisions operating in the federal subjects of the Russian Federation; currently, Roshydromet has interagency cooperation agreements with governments of 77 subjects of the Russian Federation. At present, the Unified State Monitoring System (partly including environmental monitoring) is developed within the framework of the Northern Fleet Joint Strategic Command (JSC). The JSC's area of responsibility includes the Arctic seas and coast.

Notably, despite the increase in actual prices, the expenditures on environmental protection in the Russian Federation have been steadily declining since 2004 (Table 1) and, since 2014 , make up only $0.7 \%$ of the GDP.

Table 1. Volume index of environmental expenditures (as \% of previous year, in comparable prices).

\begin{tabular}{|l|c|c|c|c|c|}
\hline $\begin{array}{l}\text { Volume index of environmental } \\
\text { expenditures, total }\end{array}$ & $\mathbf{2 0 1 3}$ & $\mathbf{2 0 1 4}^{*}$ & $\mathbf{2 0 1 5}$ & $\mathbf{2 0 1 6}$ & $\mathbf{2 0 1 7}$ \\
\hline Russian Federation & 101.9 & 105.8 & 92.8 & 92.8 & 102.7 \\
\hline Russian Arctic Zone & - & - & 115.8 & 83.3 & 132.7 \\
\hline
\end{tabular}


*The data for the Republic of Crimea and Sevastopol are not included.

We should note that a slight increase in environmental expenditures can be observed for the Russian Arctic Zone. The major portion of the expenditures is spent on wastewater treatment $(36 \%)$, while the expenditures on land rehabilitation and biodiversity conservation are only $5 \%$ and $6 \%$, respectively.

\section{Organization of environmental planning and management; organization of environmental monitoring}

The system for environmental planning and managing the development of the Russian Arctic cannot be organized without its most crucial element that is monitoring of industrial development of the Arctic's energy resources. This is a complex problem that can be solved only with the help of modern computer technologies and innovations. First of all, common standards should be adopted for the existing legal framework, which currently does not comply with the "Foundations of the Russian Federation's State Policy in the Arctic Until 2020 And Beyond". A number of critical goals can be achieved through unification of standards, including:

- generating fundamental nation-wide regulations subsequently serving as the basis for working out sectoral and territorial regulations;

- unifying the regulations and standards of different agencies governing the activities in the Arctic Zone in view of its environmental specifics;

- taking into account modern recommendations of international organizations in the field of environmental protection;

- devising mechanisms for rapid collection of new data on the structural and functional organization of Arctic ecosystems;

- devising mechanisms for regional adaptation and testing of technologies for extraction and processing of natural resources in the Arctic;

- taking into account the considerable diversity of the Russian Arctic Zone;

- developing approaches to determining the permissible limits for anthropogenic impact on Arctic (and many other) ecosystems;

- ensuring transparency and accessibility of the documents regulating environmental standards and standards of economic activity in the Arctic;

- organizing a system of indicators to determine the permissible limits of anthropogenic impact on Arctic ecosystems and providing access to the monitoring results in real time;

- organizing a system for feedback (for data collection, processing and control) from enterprises, administrations and population of the Arctic Zone.

Information support of a unified system for environmental planning and managing the development of the Russian Arctic should potentially include a unified consolidated data bank containing the results of industrial and environmental monitoring:

The unified system of environmental planning and management should be integrated, as far as possible, with other existing information systems. Structured information on environmental megaprojects implemented in the Arctic Zone should be readily accessible to state and regional structures, helping with making management decisions. The specific data and its security classification should be determined by the administrator, but the general trend should be aimed at increasing transparency and accessibility of environmental information, including that available to residents of the Russian Arctic regions. 


\section{Conclusions}

Putting the above proposals into practice would clearly entail considerable costs. However, the principles of transparency and accessibility make it possible to find forms and methods of interaction between government bodies, companies and the public. The opportunities offered by the digital business provide new tools for attracting stakeholders to finance projects, which can reduce budget expenditures on monitoring. A systemic approach to organizing the system for environmental planning and management of territory development in the context of rapid expansion of the extraction and processing industry should establish both effective control of the environmental status and the public health, and the option to actively affect the situation.

\section{Acknowledgments}

The paper has been completed in accordance with the basic part of the state assignment to higher educational institutions of the Ministry of Education and Science of the Russian Federation regarding research initiatives on the topic "Improving the Methods of Operational and Long-Term Diagnostics of Marine Hydrobionts Habitat under the Conditions of Active Industrial Development of Hydrocarbons in the Arctic Shelf', no. 13.11485.2017/БЧ.

\section{References}

1. B. Kaiser, L. Fernandez, N. Vestergaard, Polar Journal 6(1), 152-168 (2016)

2. K. Tervo-Kankare, E. Kaján, J. Saarinen, Finland Tourism Geographies 20(2), 202 (2018)

3. L. Heininen, Northern Research Forum, 67-81 http://www.oxfordenergy.org/wpcms/wp-content/uploads/2014/11/WPM-56.pdf

4. E. Bashmakova, V. Selin, Bulletin of the Kola Scientific Center of the Russian Academy of Sciences 2(13), 98-108 (2013)

5. A. Moe, In Asia and the Arctic (Springer, Singapore, 2016)

6. S. Agarkov, T. Motina, D. Matviishin, IOP Conf. Series: Earth and Environmental Science 180, 012007 (2018) doi :10.1088/1755-1315/180/1/012007

7. S. Agarkov, D. Matviyishin, Izvestiya of the St. Petersburg State Economic University 3(105), 55 (2017)

8. A. Martinov, Report on scientific research, Estimation of anthropogenic impacts of large industrial enterprises on the main types of ecosystems in the Russian Arctic taking into account their assimilation potential (2007) https://arcticregion.ru/index.php/ekologiya-arktiki

9. G. Matishov, Integrated research of large marine ecosystems in Russia (KSC RAS, Apatity, 2011)

10. K. Atland, Comparative Strategy B 33(2), 145 (2014)

11. H. Peimani, Energy security and geopolitics in the Arctic: Challenges and opportunities in the 21st Century (World Scientific, 2013)

12. R. Ingvaldsen, Polar Biology 40(10), 2105 (2017)

13. M. Zhumadilova, Zh. Zhumadilova, Knowledge. Understanding. Skill 1 (2014)

14. K. Novruzova, A. Tataraev, Russian scientific journal 1(54), 184 (2017) 
15. I. Ilin, O. Iliashenko, A. Borremans, Proceedings of the 30th International Business Information Management Association Conference, IBIMA 2017 - Vision 2020: Sustainable Economic development, Innovation Management, and Global Growth 2729 (2017)

16. I. Zaychenko, I. Ilin, A. Lyovina, Proceedings of the 31st International Business Information Management Association Conference (IBIMA) 4652 (2017)

17. T. Alesinskaya, D. Arutyunova, V. Orlova, I. Ilin, S. Shirokova, Academy of Strategic Management 16(1), 10 (2017)

18. A. Cherepovitsyn, S. Lipina, O. Evseeva, Journal of Mining Institute 232, 438 (2018) DOI: 10.31897/PMI.2018.4.438

19. A. Kozmenko, S. Teslya, S. Fedoseev, IOP Conference Series: Earth and Environmental Science 180, 1 (2018)

20. S. Agarkov, A. Kozlov, S. Fedoseev, A. Teslya, Journal of Mining Institute 230, 209 (2018) DOI: 10.25515 / PMI.2018.2.209 